\title{
Carrier testing for spinal muscular atrophy
}

\author{
Jonathan M. Gitlin, $P h D^{1}$, Kenneth Fischbeck, $M D^{2}$, Thomas O. Crawford, $M D^{3}$, Valerie Cwik, $M D^{4}$, \\ Alan Fleischman, $M D^{5}$, Karla Gonye, $M B A^{6}$, Deborah Heine, $\mathrm{JD}^{7}$, Kenneth Hobby ${ }^{8}$, \\ Petra Kaufmann, $M D^{2}$, Steven Keiles, MS, CGC ${ }^{9}$, Alex MacKenzie, PhD ${ }^{10}$, Thomas Musci, $M D^{11}$, \\ Thomas Prior, $P h D^{12}$, Michele Lloyd-Puryear, $M D, P h D^{13}$, Elaine A. Sugarman, $M S, C G C^{14}$, \\ Sharon F. Terry, $M A^{15}$, Tiina Urv, PhD ${ }^{16}$, Ching Wang, MD, PhD ${ }^{17}$, Michael Watson, MS, PhD ${ }^{18}$, \\ Yuval Yaron, $M D^{19}$, Phyllis Frosst, PhD ${ }^{I}$, and R. Rodney Howell, $M D^{20}$
}

\begin{abstract}
Spinal muscular atrophy is the most common fatal hereditary disease among newborns and infants. There is as yet no effective treatment. Although a carrier test is available, currently there is disagreement among professional medical societies who proffer standards of care as to whether or not carrier screening for spinal muscular atrophy should be offered as part of routine reproductive care. This leaves health care providers without clear guidance. In fall 2009, a meeting was held by National Institutes of Health to examine the scientific basis for spinal muscular atrophy carrier screening and to consider the issues that accompany such screening. In this article, the meeting participants summarize the discussions and conclude that pan-ethnic carrier screening for spinal muscular atrophy is technically feasible and that the specific study of implementing a spinal muscular atrophy carrier screening program raises broader issues about determining the scope and specifics of carrier screening in general. Genet Med 2010:12(10):621-622.
\end{abstract}

Key Words: spinal muscular atrophy, carrier screening, national standards, policy, meeting report

$\mathrm{O}$ September 30, 2009, the National Human Genome Research Institute, the Eunice Kennedy Shriver National Institute of Child Health and Human Development, and the National Institute of Neurological Disorders and Stroke convened a group of stakeholders, including experts in spinal muscular atrophy (SMA), professional medical societies, and SMA patient advocacy groups, for a meeting entitled "Examining the Scientific Basis for SMA Carrier Screening" at the National Institutes of Health (NIH) in Bethesda, MD, to examine the scientific basis and explore diverse

From the ${ }^{1}$ National Human Genome Research Institute; ${ }^{2}$ National Institute for Neurological Disorders and Stroke; ${ }^{3}$ Johns Hopkins University; ${ }^{4}$ Muscular Dystrophy Association; ${ }^{5}$ March of Dimes Foundation; ${ }^{6}$ Athena Diagnostics, Inc; ${ }^{7}$ Claire Altman Heine Foundation, Inc; ${ }^{8}$ Families of SMA; ${ }^{9}$ National Society of Genetic Counselors; ${ }^{10}$ University of Ottawa; ${ }^{11}$ American College of Obstetricians and Gynecologists; ${ }^{12}$ The Ohio State University; ${ }^{13}$ Health Resources and Services Administration; ${ }^{14}$ Genzyme Genetics; ${ }^{15}$ Genetic Alliance; ${ }^{16}$ Eunice Kennedy Shriver National Institute of Child Health and Human Development; ${ }^{17}$ Stanford University Medical Center; ${ }^{18}$ American College of Medical Genetics; ${ }^{19} \mathrm{Tel}$ Aviv Sourasky Medical Center; and ${ }^{20}$ Miller School of Medicine, University of Miami.

Jonathan M. Gitlin, National Human Genome Research Institute, 31 Center Drive, 4B09, Bethesda, MD, 20892-2152. E-mail: gitlinjm@mail.nih.gov.

Disclosure: For disclosure statements please see acknowledgements.

The opinions and assertions contained herein are the private views of the authors and are not to be construed as official or as reflecting the views of the National Human Genome Research Institute, the National Institute for Neurological Disorders and Stroke, the Eunice Kennedy Shriver National Institute of Child Health and Human Development, or the National Institutes of Health, Health Resources and Services Administration or the Department of Health and Human Services.

Published online ahead of print August 30, 2010.

DOI: 10.1097/GIM.0b013e3181ef6079 views on SMA carrier testing. SMA is an autosomal recessive disease characterized by progressive degeneration of motor neurons in the spinal cord. Currently, there is no treatment or cure, and SMA is the most common inherited cause of early childhood death. Although the meeting was convened to discuss issues specific to carrier screening for SMA, during discussion it became clear that there are broader implications that will affect many other inherited diseases.

Several groups, including companies that are developing or offering screening tests, presented their experience with carrier screening for SMA in the United States and abroad. Israel has been a proponent of carrier screening for a number of genetic diseases and currently offers SMA carrier screening to all couples as part of routine reproductive care. In Israel, the Society of Medical Genetics proposed adding SMA to the recommended list of carrier screening tests in 2007 , and $90 \%$ of the individuals who have chosen genetic testing for other conditions and were informed about SMA carrier testing elected to have it. Israel has fewer births each year than the United States, 150,000 births a year compared with $>4$ million in the United States.

Genzyme Genetics, a laboratory services provider that licensed SMA carrier testing in 2008 from Athena Diagnostics, presented their experience with carrier testing for SMA in the United States. Genzyme has performed SMA carrier testing to more than 72,000 individuals, $94.5 \%$ of whom had no family history of SMA (unpublished data). In an earlier published study, Genzyme used a sample of 5,000 individuals and found SMA carrier frequency to be highest in the Caucasian population (1:35), decreasing in frequency for Asians (1:53), African-Americans (1:66), and Hispanics (1:117). Overall, Genzyme calculated a $>90 \%$ SMA carrier detection rate for all ethnic groups, except for African-Americans, where it is estimated to be $\sim 70 \%{ }^{1}$

Carrier screening for SMA has been performed since 1996 at Ohio State University, mostly for families with a history of the disease. Recently, a small-scale population-based carrier screening study $(n=500)$ was conducted for individuals with no family history of the disease. ${ }^{2}$ The study indicated a carrier frequency of 1:31 in Caucasians. Furthermore, the study found the majority of patients $(98.7 \%)$ who pursued SMA carrier testing responded favorably to the experience and only one patient responded unfavorably because of added anxiety. Survey results also indicated that although there is a general lack of familiarity with SMA, there is general interest in carrier screening for SMA. Finally, the study found that the information necessary for individuals to make an informed decision regarding carrier testing for SMA can be presented effectively and efficiently through a counseling session enhanced by printed educational material.

In November 2008, the American College of Medical Genetics (ACMG) released a position statement recommending that SMA carrier screening be offered to all pregnant couples or those con- 
sidering a pregnancy. ${ }^{3}$ In May 2009, the American College of Obstetrics and Gynecology (ACOG) released a position statement recommending that SMA carrier screening be offered only to those requesting the test or who had a family history of SMA. ${ }^{4}$ The difference of opinion between these professional medical communities has left health care providers without clear guidance concerning SMA carrier testing. ACOG differed with ACMG and did not recommend the adoption of routine screening, citing insufficient pilot data, low frequency of the disease, lack of data on cost-effectiveness, inadequate access to counseling, insufficient provider education, and the high price of the test.

Traditional factors considered when assessing whether or not to recommend a carrier screening test for a hereditary condition include the impact of the disease in the affected offspring, frequency of carriers in the population to be screened, availability of technically and clinically valid screening methods that are reasonably priced, voluntary provision of the testing with appropriate informed consent, and availability of effective pre- and posttest counseling. Given the changes in technology and attitudes toward screening, moving forward, it will be helpful to reexamine these criteria. In addition, it will be important to consider the value placed by prospective parents on such screening and include these perspectives within the professional community deliberations to achieve consensus.

In assessing whether or not it would be appropriate to recommend carrier screening for SMA, it is illustrative to look to the example of cystic fibrosis (CF). In 1997, the NIH held a consensus development conference, which resulted in the publication of a consensus statement recommending that CF screening be offered not only to adults with a family history of CF and partners of people with $\mathrm{CF}$ but also to all planning a pregnancy and to all those seeking prenatal testing. The plan was to phase in the recommendation for screening to allow sufficient "infrastructure" (e.g., care provider education) to be put in place. In 2001, ACOG and ACMG issued clinical, educational, and laboratory guidelines suggesting that $\mathrm{CF}$ carrier screening be offered as recommended by the NIH Consensus Conference on Cystic Fibrosis. This resulted in a 7 - to 10 -fold increase in $\mathrm{CF}$ testing within 18 months, providing evidence that professional society guidelines and a national consensus conference can have an important impact on physician behavior. Before the introduction of carrier screening for $\mathrm{CF}$, there was apprehension that implementation of such a screen would lead to a reduction in efforts to develop treatment for the disease. This concern has also been raised regarding SMA carrier screening. However, in the case of $\mathrm{CF}$, there is little evidence to suggest an impact of carrier screening on therapeutic development. ${ }^{5}$

As multiplex carrier screening for hundreds of diseases becomes a reality, a rational decision-making process for carrier testing is sorely needed. This requires guidelines and criteria that represent a balanced view, as was recognized at an NIH workshop held in February 2008. ${ }^{6}$ Currently, no federal advisory body evaluates or routinely recommends disorders for carrier screening, as does the Advisory Committee on Heritable Diseases in Newborns and Children (ACHDNC) for proposed disorders for newborn screening. However, the ACHDNC has recently begun reviewing carrier screening and is forming a working group to explore carrier screening issues more broadly. Members of the Secretary's Advisory Committee on Genetics, Health, and Society will be participating in the working group. The consensus of meeting participants was that in order to effectively address the broader issues affecting many diseases, including SMA, a federal process such as that begun by the ACHDNC will be needed to balance stakeholder interests, values, and ethical considerations in making recommendations on carrier screening programs.

It would be beneficial, both for SMA in particular, and carrier screening in general, for this meeting to have served as a starting point for discussion among the wider community. The pace of technology development will lower costs and barriers to access, perhaps faster than decisions can be made about the public health, population health, and public policy implications. A point that was raised by a number of participants during discussion was the need for greater collaboration between medical disciplines and for the knowledge synthesized to make its way into medical education more rapidly than has been the case in the past. There will also need to be thought given to issues of informed consent, intellectual property, as well as of health economics. We hope that this discussion among stakeholders will take place in a constructive manner, and that it shall benefit not just the SMA community but society at large.

\section{ACKNOWLEDGMENTS}

The Claire Altman Heine Foundation, Inc, funded Dr Prior's pilot study mentioned in the article.

Before assuming her current position at the NINDS, Petra Kaufmann was a recipient of research funding from the NIH, the Department of Defense, and the SMA Foundation. Petra Kaufmann has served as a consultant to the SMA Foundation. Karla Gonye is an employee of Athena Diagnostics.

Elaine A. Sugarman is an employee of Genzyme Genetics. Sharon F. Terry and Mike Watson hold grants from HRSA. Michael Watson raises funds from industry in support of the educational activities of the American College of Medical Genetics Foundation. The remaining authors have no conflicts of interest to disclose.

\section{REFERENCES}

1. Hendrickson BC, Donohoe C, Arkmaev VR, et al. Differences in SMN1 allele frequencies among ethnic groups within North America. J Med Genet 2009; 46:641-644.

2. Prior TW, Snyder PJ, Rink BD, et al. Newborn and carrier screening for spinal muscular atrophy. Am J Med Genet Part A 2010;152A:16081616.

3. Prior T. ACMG Practice Guidelines Carrier screening for spinal muscular atrophy. Genet Med 2008;10:840-842.

4. ACOG Committee on Genetics. ACOG committee opinion No. 432: spinal muscular atrophy. Obstet Gynecol 2009;113:1194-1196.

5. http://report.nih.gov/ accessed 4/13/2009.

6. National Human Genome Research Institute. Summary of population-based carrier screening for single-gene disorders: lessons learned and new opportunities. Rockville, MD, 2008. Available at: http://www.genome.gov/ 27026048. Accessed May 2010. 